\title{
Commiphora wightii (Arn.) Bhandari. Review of Its Botany, Medicinal Uses, Pharmacological Activities and Phytochemistry
}

\author{
Manisha Bhardwaj*, Aparna Alia \\ Department of Botany, Rajeev Gandhi College, Trilanga, Bhopal-462039, (M.P), India.
}

\begin{abstract}
The oldest remedies identified to mankind are herbal medicines. India is recognized worldwide for its Ayurvedic treatment. As only little studies are done on this plant, the purpose of current review is to make accessible up-to-date information on, botany, morphology, ecological biodiversity, medicinal uses, phytochemistry and pharmacological activities on diverse parts of Commiphora wightii (Arn.) Bhandari (C. wightii). This review was assembled using scientific literature from electronic search engine such as Springerlink, BioMed Central, Pub Med, Scopus, ScienceDirect, Scielo, Medline and Science domain. Supplementary literatures were obtained from books, book chapters, dissertations, websites and other scientific publications. C. wightii (Syn. Commiphora mukul Hook. ex. Stocks) or Guggulu tree. C. wightii is a shrub or small tree belonging to Burseraceae family. $C$. wightii contains volatile oil, gum resin, gugulipids, guggulsterones, guggulsterols, mukolol and other steroids. Guggulu is very much used in Ayuvedic system of medicine as astringent, anti-septic, expectorant, aphrodisiac, carminative, antispasmodic, emmenagogue. In Ayurveda, it is the best among herbs that are used for Medoroga and Vata disorders. It is widely used for obesity and it is also known as fat burning agent all over the world. It helps to lower cholesterol and triglycerides level. It is very effective in rheumatoid arthritis, gout and sciatica. It is also one of the most important Rasayana of Ayurveda. In addition it treats sluggish liver, stimulates libido nervous diseases, bronchial congestion, cardiac and circulatory problems, weak digestion, wounds, abscess, foetid ear, fractu res, gynaecological problems and various skin diseases. $C$. wightii is a very important and trustworthy herb in Ayurvedic medicine. This alternative system of medicine is gaining increasing fame universal. There is a required to isolate active constituents, their biological test, molecular mechanisms, experimental defense and legalization of therapeutic uses of $C$. wightii. The collected information will be obliging to locate up study protocol for current drugs and Ayurvedic formulation extension in remedial and luxury a variety of ailments. Clinical trials for the reported preclinical studies should be executed immediately to further validate the claims on humans.
\end{abstract}

Keywords: Commiphora wightii, Phytochemistry, Pharmacological activity, Ayurveda, Medicinal uses

Article Info: Received 11 June 2019; $\quad$ Review Completed 21 July 2019; $\quad$ Accepted 23 July 2019; Available online 15 August 2019

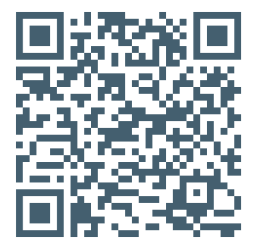

Cite this article as:

Bhardwaj M, Alia A, Commiphora wightii (Arn.) Bhandari. Review of Its Botany, Medicinal Uses, Pharmacological Activities and Phytochemistry, Journal of Drug Delivery and Therapeutics. 2019; 9(4-s):613-621

http://dx.doi.org/10.22270/jddt.v9i4-s.3256

Manisha Bhardwaj, Department of Botany, Rajeev Gandhi College, Trilanga, Bhopal-462039, (M.P), India.

\section{Introduction}

Plants are significant to human being for his life. Plants are incessantly an ordinary source of medicine in the usage of traditional preparations. All plants phyla create official and illegal product of therapeutic significance. The antiquity of herbal medicine is as very old as human society. The treasure of India is stored in the huge natural flora, which has been advantage to mankind. India is almost herbarium of the planet ${ }^{1,2}$. Although the biologically active phytoconstituents of certain herbal drugs are unidentified, they are prescribed normally owing to their effectiveness, least side effects in clinical information and moderately very low costs ${ }^{3}$. Ornamental plants are grown for decorative purposes in gardens and scenery design projects, as house plants, for cut flowers and specimen exhibit. Ornamentals and flowers harvests are not only grown for the exhibit of aesthetic features, but also have nutritive and therapeutic properties. There has been rehabilitated interest in utilizing garden environments having therapeutic value, as therapeutic entities to improve the process of healing that occurs in healthcare environments. The use of plant complexes for pharmaceutical purpose has steadily increased in India, about $85 \%$ of individuals from urbanized countries use customary medicine, which involves compounds resulting from medicinal plants 4 . Flowering trees are now being browbeaten in the customary medicine and their curative potentials are well recognized. $C$. wightii with common names Indian bdellium tree, Gugal, Guggul, Guggulu, is a flowering plant belonging to family Burseraceae. The Guggul plant may be found from northern Africa to central Asia, but is most common in Northern India. It prefers arid and semi-arid climates and is tolerant of poor 
soil. It is a shrub or small tree, reaching a maximum height of $3 \mathrm{~m}$, with thin papery bark. $C$. wightii produces a resinous sap known as gum Guggul. The extract of this gum, called gugulipid or guglipid, has been used in Ayuvedic medicine abundantly. $C$. wightii contains essential oil, resin, gum, and bitter compounds. The major chemical constituents of $C$. wightii are Z- guggulsterone, E-guggulsterone, guggullignans I \& II, gugglu tetrols; mukulol; allylcembrol; c27 guggulusterols I, II, III; Z-guggulusterol; E-guggulusterol etc. These constituents are responsible for several pharmacological activities like anti-inflammatory, analgesic, cleaning of wound and healing due to its antibacterial action. C. wightii is a natural health product used primarily to reduce elevated blood cholesterol levels. It has been used for many years as a hypocholesterolaemic agent in India. $C$. wightii is one of the best rewarding herbs for Vata diseases. Various preparations of $C$. wightii used in sciatica, hemiplegia, gout, rheumatic diseases, facial paralysis etc. $C$. wightii is beneficial in cleansing and healing of wounds and to reduce oedema due to its anti-inflammatory and antiseptic properties. In digestive ailments also like anorexia, flatulence, worm infestations, piles etc, it works well5,6. $C$. wightii is known as Marudeshya because it is a plant which grows in arid zone. It exudes a gum resin coming out of cavities (Kaushika, Ulukhala, Kumbholukhala) in form of particles (Kananiryasa) reddish black in colour (Mahishaksa, Kalaniryasa). It removes a number of ailments (Guggulu) particularly obesity (Palankasa) and is antiseptic (Rakshoha) as fumigation. It is also used as incense in god's worship (Devadhupa) ${ }^{7}$. C. wightii is known as Ulukhala because it exudes a gum-resin which comes out from cavities. The resin is the best medicine, so it is known as Pura. It is also known as Durg because it is a plant which grows in arid zone ${ }^{8}$. The classification of $C$. wightii consist of domain: Eukaryota, kingdom: Plantae, sub-kingdom: Tracheobionta, division: Magnoliophyta, class: Spermatopsida, sub-class: Magnoliidae, order: Sapindales, genus: Commiphora, family: Burseraceae, species: wightii ${ }^{9}$. The vernacular names of the plant is Mukul, Guggul, Gugal, Gogil, (Hindi), Gukkal, Gukkulu, Maishakshi (Tamil), Guggala, Gulag, Mukul (Marathi), Gugal, Gugali, Gugar, Guggul, Mukul, (Gujarat ), Gugul, Mahisaksh, Maisakshi (Telgu) Aflatan, Moql, Moqlearzaqi, Mukulearabi (Arabic), Bhavabhishtha, Bhutahara, ect (Sanskrit) ${ }^{10}$. Therefore, in this study, the ethnopharmacological review of $C$. wightii was carried out aimed at providing a detailed précis of the botany, ethnomedicinal uses, pharmacological activities and chemical composition of the species.

\section{Research methodology}

To recognize pertinent information on the botany, medicinal uses, phytochemistry and biological activities of $C$. wightii, a review was compiled based on scientific literature from various sources including Google Scholar, Web of Science, SciFinder, Scopus, Science Direct, PubMed, Scielo, Springerlink, Google Patents, Espacenet, BioMed Central (BMC) and Medline. The keywords used for recognition of relevant data included dissimilar scientific name and synonyms, common English names, and the terms: biological activities, medicinal uses, ethnobotany, ethnopharmacology, medicinal, pharmacology, phytochemistry and therapeutic value, C. wightii, Commiphora mukul Hook. ex. Stocks. Further literatures were obtained from books, book chapters, theses, websites and conference proceedings.

\section{Occurrence and distribution}

The $C$. wightii plant present in arid and semi arid climate and it's tolerant of poor soil. The $C$. wightii plant mainly distributed in arid area of northern Africa to central Asia, but it most common in Rocky track of western India and Eastern Himalayas. In central Asia the $C$. wightii plant is distributed in arid areas of India, Bangladesh and Pakistan. In India it plant found in arid, Rocky tracts of Rajasthan, Gujarat, Maharashtra, Madhya Pradesh and Karnataka. According to Ayurveda, there are five type of Guggul namely; Krishnan (black), Peet Varn (Yellow), Neel (blue), Kapish (light brown) and Rakt (blood red). It is propagated by seeds and root cuttings ${ }^{11-13}$.

\section{Morphology}

C. wightii is a woody shrub or a small tree which grows to the height of 2-3 metres, much branched with characteristics silvery and paper like bark-peelings. Branches are knotty and crooked, divaricate, usually ending in a sharp spine. Leaves: The leaves are rhomboid-ovate, 1-3 foliate, serratetoothed in the upper part, smooth and shinning, the lateral leaflets when present less than half the size of the terminal ones. Flowers: Flowers in the fascicles of 2-3; pedicles very short. Calyx campanulate, glandular, hairy; lobes are 4-5 in number, triangular, as long as the tube. Petals are brownish red, broadly linear, nearly thrice the length of the calyx, reflexed at the apex. Stamens are 8-10 in number, alternatively long and short, half the length of the petals. Disk, 8-10 lobed, the alternate sinuses deeper and in these are inserted the shorter stamens. Ovary oblong-ovoid, attenuated into the style. Fruits: The fruits are small, red in colour when ripe, ovoid drupes. Each plant produces about 0.5 to $1 \mathrm{~kg}$ of oleo-gum resin which is collected from January to March. Gum Resin: Pale yellow to brown aromatic gum resin obtained from the bark of the plant. Agglomerated tears of resin are somewhat transparent, with waxy surface and brittle in nature. Gum-resin is thick, scented, burnt on fire, liquifies in sun heat. When dissolved in water, it turns milky white ${ }^{14-16 .}$

\section{Macroscopic and microscopic features}

Macroscopic $C$. wightii occurs in vermicular pieces of pale yellow or brown colored mass with aromatic odour and bitter astringent taste; when fresh it is viscid and golden colored. Makes milky emulsion in hot water and readily burns. Tears of varying sizes, reddish yellow or brown in color, more often occurring in resinous lumps which turn darker in color on long storage. Fracture-brittle, exposing a rough or waxy surface having a moist unctuous appearance; balsamic odour, acrid, bitter and aromatic taste.

Microscopic Foreign matter Not more than $4 \%$; Total Ash Not more than $5 \%$; Acid-insoluble ash Not more than 1\%; Alcohol-soluble extractive Not less than $27 \%$; Water-soluble extractive Not less than 53\%; Volatile oil Not less than $1 \%$, $\mathrm{v} / \mathrm{w}$ and between 1.0 and 1.5 percent of guggulsterones $(Z$ and $E)^{17,18}$.

\section{Phytochemical constituents}

C. wightii contains diterpenoids, triterpenoids, steroids, longchain aliphatic tetrols, aliphatic esters, ferulates, lignans, carbohydrates, and a variety of inorganic ions besides minor amounts of sesamin and other unidentified constituents.

\section{Volatile oil and its terpenoidal constituents}

Monoterpenoids The gum resin of $C$. wightii yields about $0.4 \%$ of essential oil by steam distillation and its chief components are myrcene, dimyrcene, and polymyrcene ${ }^{19}$. Other components of the oil are eugenol, d-limonene, $\alpha$ pinene, $( \pm)$ linalool, cineole, $\alpha$-terpineol, d- $\alpha$-phellandrene, methylheptanone, bornyl acetate, $( \pm)$ geraniol, and some other unidentified compounds ${ }^{20}$. 
Sesquiterpenoids The gum resin of $C$. wightii has been reported to contain bicyclic sesquiterpene, cadinene ${ }^{20}$.

Diterpenoids Diterpenoid constituents from guggulu include $\alpha$-camphorene, cembrene-A, cembrene 21 and other cembrenoids. Cembrene-A is one of the most elementary tetraenes derived from geranylgeranyl pyrophosphate by C1 to C-14 cyclization. Mukulol (allylcembrol) is a new cembrane alcohol which was isolated from the aerial parts and also from the resin of guggulu ${ }^{22,23}$. The allylcembrol structure was established by spectral analysis and mild dehydration which yielded cembrene. Other isolated cembrane type diterpenes include isocembrol and 4epiisocembro. $\quad(1 E, \quad 4 E, \quad 8 E)$-4,8,14-Trimethyl11-(1methylethyl)4-methoxycyclotertradeca-1,4,8-triene, $\quad(2 E$, $12 E)-2,7,13$-trimethyl-9-(1-methylethyl)-15- oxabicyclo [12.1.0] pentadeca-2,12-diene-7-ol and $(4 Z, 6 E)$ 4,7,12,15,15-pentamethylbicylco [9.3.1] pentadeca-4,6diene-12-olwere novel compounds obtained by bioassayguided isolation from hexane-soluble portion of the methanol extract of guggulu 24 .

Triterpenoids Polypodane-type triperpenes, myrrhanol A, B, and $\mathrm{C}$, myrrhanone $\mathrm{A}$, myrrhanone $\mathrm{B}$, myrrhanone $\mathrm{A}$ acetate, commipherol, commipherin, and octanordammarane triperpenoid, epimansumbinol have been isolated from the gum resin. The isolation of two more triterpenoidal components has been reported, which are identified as mansumbinone and mansumbinoic acid $25-28$. The absolute stereo structure of myrrhanol A was determined to be $(3 S$, $5 S, 8 R, 9 R, 10 S)-3,8,30$-trihydroxypolypoda- $13 E, 17 E, 21 E$ triene. Myrrhanol B is 30-oic acid of myrrhanol A with altered stereostructure at $\mathrm{C}-5(5 R$ in contrast to $5 S$ in myrrhanol A). Myrrhanone A and B are 3-keto analogue of myrrhanol $A$ and $B$, respectively ${ }^{26}$. A myrrhanone derivative, $(13 E, 17 E, 21 E)$-8-hydroxypolypoda-13, 17, 21-trien-3-one and a myrrhanol derivative, $(13 E, 17 E, 21 E)$-polypoda-13, 17,21 -trien-3, 18-diol have also been isolated ${ }^{24}$.

2. Steroids Isolation of several steroidal constituents has been reported from the gum resin. The major constituents include E-guggulsterone, Z-guggulsterone, guggulsterol-1, guggulsterolII, guggulsterol-III, guggulsterol-IV, guggulsterol-V and guggulsterol-VI. Other isolated steroids are $20 \alpha$-hydroxy-4-pregnen-3-one, $20 \beta$-hydroxy-4-pregnen3-one, and 16 $\beta$ - hydroxy-4, 17 (20)-Z-pregnadien-3-ones which has been designated as Z-guggulsterol $29-32$. Progesterone and related steroids, 4-pregnene-3, 16-dione, (20R)20 -acetoxy-4-pregnene-3,16-dione, $16 \beta$ acetyloxypregn $4,17(20)$-trans-diene-3-one, $3 \alpha$-acetyloxy $5 \alpha$ pregnan-16-one and 20R,22R-dihydroxycholest-4-en-3-one have also been isolated ${ }^{27}$. Cholesterol has also been reported. Three new and recently isolated steroids are guggulsterone- $\mathrm{M}$, dihydro guggulsterone- $\mathrm{M}$ and guggulsterol-Y28. The steroidal constituents have been related with hypolipidemic and anti-inflammatory activities of the drug 24 .

3. Flavonoids An ethanolic extract of trunk of $C$. wightii was separated on column packed with silica gel to give a new antifungal flavone named muscanone along with known naringenin. Muscanone was found to be active against $C$. albicans in microbial sensitive assay. The major flavonoid components of the flowers of $C$. wightii were identified as quercetin, quercetin-3-0- $\alpha$-L-arabinose), quercetin3-0- $\beta$-Dglucuronide, quercetin-3-0- $\beta$-Dgalactoside, quercetin-3-0- $\alpha$ L-rhamnoside and pelargonidin-3, 5, di-O-glucoside ${ }^{32,33}$.

4. Guggultetrols A crystalline material was isolated from the saponified gum resin which was characterized as a mixture of octadecan-1,2,3,4-tetrol, nonadecan1,2,3,4-tetrol and eicosan-1,2,3,4-tetrol with minor amount of other components, possibly lower (C-16 and C-17) and higher (C21 and C-22) homologous tetrols. These compounds constitute a new class of naturally occurring lipids, guggultetrols. They are long-chain linear aliphatic tetrols with hydroxyl functions at C-1, C-2, C3, and C-4 positions. Through derivatization and preparative GLC, guggultetrol-18 and guggultetrol-20 were obtained in pure form. A mixture of two ferulates $(n=16,17)$ with an unusual skeleton was found to be responsible for the cytotoxic action of the drug. They have been isolated from cytotoxic fraction of ethyl acetate extract of guggulu. It was identified as a mixture of esters based on homologous longchain tetrols and acid ${ }^{34,35}$.

5. Lignans Two lignans, sesamin ${ }^{29}$ and diayangambin ${ }^{36}$ have been reported from guggulu. Also, 5,5-tetrahydro- $1 \mathrm{H}, 3 \mathrm{H}$ furo[3,4-c]furan-1,4-diylbis[7- (methoxy)-1,3-benzodioxole] has been reported from methanolic extract of guggulu 24 .

6. Sugars Complete hydrolysis of gum part of resin yielded L-arabinose, D-galactose, L-fructose (traces) and 4-Omethyl-D-glucuronic acid. Graded hydrolysis of the gum furnished an aldobiouronic acid [6-0-(4-0-methyl- $\beta$ - Dglucopyranosyluronic acid)-D-galactose]. Hydrolysis of methylated gum furnished 2,3,4,6-tetra-0-methylDgalactose, 2,3-di-O-methyl-L-arabinose, 2,3,4-tri-OmethylD-galactose, 2,4-di-0-methyl-D-galactose, and 2,3,4tri-Omethyl-D-glucuronic acid in the ratio of $1: 1: 1: 2: 1$. The provisional structure showed the gum to be a highly branched polysaccharide containing 1-6, 1-3,- and 1-5 type of linkage 37,38 .

7. Amino Acids $C$. wightii was extracted with alcohol and the extract after removal of the solvent was partitioned between water and ether. The aqueous fraction was chromatographed and it showed the presence of various amino acids. The amino acids detected were cystine, histidine, lysine, arginine, aspartic acid, serine, glutamic acid, threonine, alanine, proline, tyrosine, tryptophan, valine, leucine, and isoleucine ${ }^{39}$.

\section{Cultivation}

C. wightii is sought for its gummy resin, which is harvested from the plant's bark through the process of tapping. In India, $C$. wightii is cultivated commercially. It can successively be propagated by vegetative means. The rooting initiates 21 days after sprouting and $300 \mathrm{~mm}$, long 15 and $15 \mathrm{~mm}$ diameter cutting gives the maximum rooting. As it is a plant of arid zone, there is no necessity of irrigation upto the middle of November except during drought. However, if there is the winter shower, there is a necessity of irrigation to plants of one to five years of age group. The plants of 6-7 years of age group require irrigation only in summer season. Irrigation can be done either by head load method or water tank method 40,41 .

\section{Medicinal uses}

The use of $C$. wightii plant in the treatment of diseases occupies an important place in ayurveda, the traditional medicine system of india. The Atharvaveda one of the four well known holy scriptures (Vedas) of the Hindus, the Atharvaveda is the earliest reference for it medicinel and therapeutic properties ${ }^{42}$. Detained description regarding it action, use and induction as well as the varieties of guggul have been described in numerous Ayurvedic treat including Charaka samhita (1000 BC), Sushruta Samhita (600 BC and Vagbhata seventh century AD). In addition, various medical lexicons were return between twelth and forteen centuries AD. It responsible for reducing fat, indicated for healing Bone Fracture to inflammation, Arthritis, Atherosclerosis, Obesity, Hyperlipidemia, Rheumatism, Haemorrhids, 
Urinary disorder, skin disease high cholesterol, neurodegenertion, Parkinson's diseases, mongolism and ageing process ${ }^{43-48}$. C. wightii is a gum resin, historically used for antiseptic and deep penetrating action in the treatment of elevated blood cholesterol and Arthritis. C. wightii is effective as weight loss and fat burning agent. It increase white blood cell count and possess strong disinfecting properties. Used as a carrier and combined with other herbs to treat specific condition $44,49,50$. Traditionally, C. wightii plant is given in the form of YOG, where in $C$. wightii is mixed with other drug's along with castor oil or Indian clarified butter. The YOG could also be prepared by cooking the $C$. wightii with water, and other herbal drug powder. Popular Ayurvedic formulated containing $C$. wightii are: Yograj gugguluvati, Pachamrit ioh guggulu, Kaishore gugguluvayi, Triphla guggulu and Sinhaguggluvati ${ }^{51}$. C. wightii has been a key component in ancient Indian Ayurvedic system of medicine and now widely use in Morden medicine for treatment of heart ailments. But $C$. wightii as it's locally known, has become so scarce because of its overuse in it two habitats in india where it found-Gujarat and Rajasthan. The extract, called guggulipid, comes from the $C$. wightii tree and has been used in Ayurvedic medicine, a traditional Hindu medicine, for nearly 3000 years in India. Today it existence is threatened because of iow seed production in an adverse natural condition and recent environmental change due to rainfall pattern and increasing level of atmospheric pollution. This plant species is fighting for its survival in the natural habitat since a long time. Attempts have been made in this direction by number of researchers including under present investigation towards its natural populations, germplasm collection, cultivation techniques, Phytosociology and regeneration potentialities etc. at different site of Western Indian Thar desert 44,52 . The oleo-gum resin commonly known as "gum guggul" or "Indian Myrrh" is the economically important product of Indian bdellium. The oleo-gum is collected as exudates from woody stem. A plant generally takes 10 years to reach tapping maturity under the dry climate conditions. The thick branch is incised during the winter to extract the oleo-gum resin. Guggul gum is a mixture of $61 \%$ resin, and $29.3 \%$ gum, in addition to $6.1 \%$ water, $0.6 \%$ volatile oil and $3.2 \%$ foreign matter 53 .

\section{Reported pharmacological activities}

\section{> Hypolipidemic/Hypocholesterolaemic activity}

1. Crude Guggulu was reported to possess highly encouraging hypolipaemic activity in rabbits 54 .

2. Anion exchange property detected by means of chloride retention and bile acid sequestrating activity in the oleoresin fraction hypocholesterolaemic activity55.

3. Crude drug as well as its two fractions (alcohol soluble and alcohol insoluble) were found to cause a significant fall in serum cholesterol and serum turbidity with a concomitant increase in the coagulation time and prothrombin time. The alcohol insoluble fraction was slightly more potent in this respect than alcohol soluble fraction as well as crude Guggulu ${ }^{56}$.

4. PE fraction A (petrol-soluble), B (alkali washed neutral portion) and C (petrol-insoluble) were given to 8 week old male white leg horn chicks for 2-3 weeks in hypercholesterolaemia induced by atherogenic diet. All fractions lower the serum cholesterol, but fraction $\mathrm{A}$ is most potent and $B$ is the least potent ${ }^{57}$.

5. Alcohol extract and two pure fractions (a terpenoid and a steroid) isolated from the PE extract showed that the steroid fraction was highly potent as hypolipaemic agent lowering the serum cholesterol by $69.3 \%$ as well as the $\mathrm{c} / \mathrm{p}$ ratio. The alcohol extract could lower the cholesterol by $59.2 \%$ whereas the Terpenoid lowered it by $54.3 \%{ }^{58}$.

6. The alcohol extract of Guggulu when orally administrated to Indian domestic pigs kept on standard atherogenic diet over a period of six weeks effectively reduced the total serum cholesterol and also serum beta-lipoprotein fraction and significantly altered the lipoprotein ratio ${ }^{59}$.

7. The steroidal compound isolated from fraction A of PE extract reduced the lipid content (Viz., total lipids, cholesterol, TG and phospholipids) of both hepatic and aortic tissues. The response was doses-dependent and the maximum effect was noted at $10 \mathrm{mg} / \mathrm{kg}^{60}$.

8. Fraction A of PE extract of $C$. mukul, effectively lowered serum lipids, cholesterol, phospholipids and triglycerides in monkeys fed with cholesterol diet 61 .

9. Alcoholic extract (25-50 mg/kg orally), reduced serum cholesterol level in normal and hyperlipaemic rats and rabbits. Further, a resin fraction, a pure steroid and fraction $F$ isolated from crude extract showed hypocholesterolaemic effect on normal and tritoninduced hyperlipaemic rats 62,63 .

10. The hypolipidemic activity was shown in animals as well as in patients of obesity and hypercholesterolemia ${ }^{64}$.

11. A number of clinical studies were carried out to confirm hypolipidemic activity of guggulu and gugulipid 65,66 .

12. In another study, highly significant reduction in levels of mean serum cholesterol and triglyceride was observed in groups of animals receiving high-fat diet for one month along with guggulu, which clearly demonstrated its hypolipidemic activity. Additionally, administration of guggulu partially reversed the atherosclerosis in the aorta that was induced by highfat diet 67 .

13. Clinical studies on C. mukul showed its hypolipidemic effect and the outcome of change in lipid profile upon its administration. This study showed significant decrease in total cholesterol and LDL cholesterol after treatment with guggulu68.

14. The hypolipidemic activity of the isomers $E$ guggulsterone andZ-guggulsterone has also been studied in animalmodels. Administration of guggulsterone $(Z$ and $E)$ significantly lowered serumlipid levels of rats with either triton (WR-1339) or cholesterol-induced hyperlipidemia ${ }^{69}$.

$>$ Effect on Platelet Aggregation and Fibrinolytic Activity

1. The purified steroid mixture from guggulu completely inhibited ADP, adrenaline, or serotonin induced platelet aggregation. No difference was observed between the effectiveness of the steroid mixture and the purified guggulsterone $E$ or $Z$. The effect of guggulsterones $E$ and $Z$ was very similar to the inhibitory effect of clofibrate. This finding has therapeutic value in myocardial infarction and thromboembolism ${ }^{70}$.

2. The effect of guggulu on fibrinolysis and platelet adhesiveness in coronary heart disease was studied. 
Guggulu fraction A (pet ether extract) in daily dose of 1 $\mathrm{g}$ was administered to healthy individuals (group I) and to patients of coronary artery disease (CAD) (group II) for a period of 30 days. Serum fibrinolytic activity increased, while the platelet adhesive index decreased, which was statistically significant in healthy individuals and in CAD patients. In view of this, guggulu fraction A may be a useful therapeutic agent in the management of coronary artery disease ${ }^{71}$.

\section{> Thyroid Stimulatory Activity}

1. Administration of ethanolic extract of guggulu to the female albino mice for 15 days enhanced the triiodothyonine (T3) concentration and T3/T4 ratio,while nomarked change in the concentrations of serum thyroxine (T4) was observed 72 .

2. Z-Guggulsterone was shown to be responsible for the thyroid stimulatory action of guggulu. Administration of isolated $Z$-guggulsterone to rats led to significant increase in all thyroid function parameters, namely, uptake of iodine by the thyroid, enzymes involved in the synthesis of thyroid hormones, and tissue oxygen uptake, thus suggesting thyroid stimulatory action ${ }^{73}$.

\section{$>$ Anti-inflammatory and Anti-arthritic activity}

1. Oleoresin was found to be highly potent antiinflammatory agent, as compared to hydrocortisone and butazoladin against Brownlee's for maldehydeinduced arthritis in albino rats ${ }^{74}$.

2. Oleoresin fraction possesed significant anti-arthritic and anti-inflammatory activities, the minimum effective dose being $12.5 \mathrm{mg} / 100 \mathrm{~g}$ body weight. Only the acidic fraction showed significant activity while the monoacid and solid fractions were inactive ${ }^{75}$.

3. The Steroidal compound isolated from PE extract possessed significant anti-inflammatory activity on carrageenin-induced rat-paw oedema76,77.

4. The results of several studies confirm antiinflammatory and antiarthritic activities of guggulu ${ }^{78-}$ 82.

5. The 50 percent aqueous methanolic extract was found to exhibit an anti-inflammatory effect on adjuvantinduced air pouch granuloma in mice. The methanolic extract inhibited nitric oxide production in lipopolysaccharide activated mouse peritoneal macrophages ${ }^{83}$.

6. Guggulosomes prepared using guggul with ibuprofen by bath sonication and trituration methods were studied for anti-inflammatory activity. It was clearly shown that guggulosomes had more efficacy than ibuprofen and both guggul and ibuprofen had synergistic effect. The study proved that guggul could serve as a carrier for entrapping drugs and for their sustained release action 84

7. Several animal studies have demonstrated the effectiveness of guggulu extract in standard osteoarthritis (OA) models. The authors had conducted both animal and clinical investigations of guggulu for OA prior to this study. The goal of this study was to determine the effectiveness of guggulu for reduction of pain, stiffness, and other symptoms that arise from $\mathrm{OA}^{85}$.

\section{$>$ Antiatherosclerotic Activity}

1. LDL has been found to accumulate in atherosclerotic lesions and is the major source of the cholesterol accumulation in human foamcells.There is evidence that LDL oxidation is essential for atherogenesis and the antioxidants that prevent this oxidation may either slow down or prevent atherogenesis. Guggulsterones, the lipidlowering components of guggulu, effectively inhibited in vitro LDL oxidation (as discussed under antioxidant action). Thus the combination of antioxidant and lipid-lowering properties of guggulu makes it especially beneficial against atherogenesis ${ }^{86}$.

\section{$>$ Cardioprotective Activity}

1. Guggulsterones are shown to be effective cardioprotectives. Myocardial necrosis induced by isoproterenol in rats caused marked increase in serum creatine phosphokinase and glutamate pyruvate transaminase. Phospholipase, xanthine oxidase, and lipid peroxides were simultaneously enhanced in ischemic heart following depletion of glycogen, phospholipids, and cholesterol. Treatment with guggulsterone at a dose of $50 \mathrm{mg} / \mathrm{kg}$ significantly protected cardiac damage as assessed by the reversal of blood and heart biochemical parameters in ischemic rats 87 .

\section{$>$ Antifertility Activity}

1. Guggulu administered orally ( 2 and $20 \mathrm{mg} / 100 \mathrm{~g}$ body weight) to female rats decreased the weight of the uterus, ovaries, and cervix, whereas glycogen and sialic acid levels in these organs increased. This suggested that guggulu may be useful as an antifertility agent ${ }^{88}$.

\section{$>$ Skin Diseases}

1. Administration of gugulipid was reported to be effective in the treatment of nodulocystic acne. A study in 21 patients found that gugulipid was as effective as tetracycline in the treatment. The patients with oily faces responded better to the gugulipid treatment ${ }^{89}$.

\section{$>$ Antihyperglycemic Activity}

1. Administration of alcoholic extract of C. mukul at a dose of $200 \mathrm{mg} / \mathrm{kg}$ for 60 continuous days reduced plasma glucose levels in streptozotocin-induced diabetic rats ${ }^{90}$.

2. A study showing effect of guggulsterone isolated from C. mukul in high-fat diet induced diabetic rats has also been reported.Different biochemical parameters like GTT, glycogen content, glucose homeostatic enzymes (like glucose-6-phosphatase and hexokinase), insulin release in vivo, and expression profiles of various genes involved in carbohydrate and lipid metabolism clearly demonstrated the hypoglycemic effect.Theresults suggested that guggulsterone has both hypoglycemic and hypolipidemic effects which can help cure type II diabetes ${ }^{91}$.

\section{$>$ Antimicrobial Activity}

1. The volatile oil of $C$ mukul was found to be highly effective against Rhyzopertha dominica which suggested its role as a fumigant. The ethanolic extract of C. mukul exhibited best antibacterial activity at $5 \mathrm{mg} /$ $\mathrm{ml}$ against multidrug-resistant Klebsiella pneumonia ${ }^{92}$.

2. An active compound, 5(1-methyl,1-aminoethyl)-5methyl-2- octanone, of the methanolic extract of guggulu gum possessed significant antibacterial 
activity against Gram-positive bacteria and moderate activity against Gram-negative bacteria ${ }^{93-95}$.

\section{$>$ Cytotoxic Activity}

1. Ferulate compounds are used in the method for prevention and treatment of abnormal cell growth and proliferation of inflammation, neoplasia, and cardiovascular disease. Ethyl acetate extract showed significant in vitro cytotoxicity. A fraction showing cytotoxic activity was characterized as a mixture of two ferulates with an unusual skeleton by spectral and chemicalmethods. This fraction also showed moderate scavenging effect against 2,2-diphenyl-1- picryl hydrazyl (DPPH) radicals ${ }^{96}$.Treatment with gugulipid significantly inhibited the viability of human prostate cancer cell line LNCaP (androgendependent)and its androgen-independent variant (C-81) with IC50 of 1 $\mu \mathrm{M}(24 \mathrm{~h}$ treatment $)$, thus indicating its possible role in apoptosis and cancer prevention ${ }^{96}$. The results of this study indicated that guggulsterone inhibited proliferation of PC-3 cells in culture by causing apoptosis, whereas a normal prostate epithelial cell line is resistant to growth inhibition and apoptosis induction by this phytoconstituent. These observations provided rationale for further preclinical andclinical evaluationof guggulsterone for its efficacy against prostate cancer ${ }^{97}$.

\section{Substitutes and Adulterants}

Oleo-gum resin obtained from Boswellia serrata Roxb. (Salai guggulu) is the major adulterant. It is distinguished by its yellowish green, golden or milky tears, seldom amalgamated into lumps and a characteristic terpentine like odour. Gumoleo-resin of Commiphora myrrha (Nees) Engl. imported from Africa and constituting the drug Hirabole or bole of commerce is sometimes mixed with Guggulu. Similarly, gumoleo-resin obtained from Commiphora roxburghii (Arn) Engl., Occurring in central and eastern India is sold by the name of Guggulu. The former is distinguished by large tears of yellowish brown colour, exposing, on fracture, a brown surface having white markings, while the latter has a bluish tinge and a feeble balasmic odour ${ }^{98}$.

\section{Possible Reasons for Its Decline}

Several reasons are cited for the plant being listed as endangered species and some of these are considered to be of greater consequences affecting its population survival. The various factors are: slow growth, poor seed-setting and seed germination rate, lack of cultivation, unsustain-able overexploitation, excessive and unscientific tapping method, invasion of alien species ${ }^{99-101}$. These have been listed below.
1. Unscientific method of tapping and overexploitation
2. Low seed setting
3. Regeneration through seeds
4. Invasion of alien species
5. Others

$\checkmark \quad$ Narrow extent of occurrence, small area of occupancy and severe fragmentation, as other reasons for conservation threat and extinction risk.

$\checkmark \quad$ It has never been brought under cultivation.

$\checkmark$ The changing environment and existing natural populations of this species has been af-fected by climatic conditions, soil erosion, low rainfall, termite infestation, over-grazing by domestic animals and mining activities.

\section{Safety and Toxicity}

It has beenmentioned in Ayurvedic texts that administration of raw guggulu may sometimes lead to skin rashes, irregular menstruation, diarrhoea, headache, mild nausea, and, with very high doses, liver toxicity ${ }^{102}$. In order to overcome the side effects of raw guggulu, Ayurveda describes a number of purification processes (shodhan vidhi) in different "dravyas," that is, fluids, which not only take care of the adverse effects but also enhance the therapeutic activity ${ }^{17}$. It is also mentioned in Ayurvedic texts that guggulu must be purified before incorporation into herbal formulations. There are a large number of commercial polyherbal antiinflammatory formulations which are using guggulu as the chief ingredient ${ }^{82}$. The clinical trials done with standardized gum guggul extracts reported transient side effects such as skin rashes, diarrhoea, and irregular menstruations. A report also states that, out of 22 individuals receiving $2160 \mathrm{mg}$ guggulu daily for 12 weeks, 10 persons experienced one or another side effect including gastrointestinal distress, fatigue, and skin rash ${ }^{103}$. Skin rashes have also been reported in other trials using 1-2 g guggulipid (ethyl acetate fraction) daily for a month. This study did not report any intestinal distress ${ }^{104}$. Although generally accepted as relatively safe, caution may be warranted during guggul consumption. There is little or no information on toxicity with the use of guggulu.

\section{Conclusion}

In the present review, we have made an effort to provide the mophological, phytochemical, ethnopharmacological and pharmacological information on $C$. wightii, a tree used conventionally for medicinal purposes. A variety of extracts and chemical compounds of the plant have shown Hypolipidemic/ hypocholesterolaemic activity, Effect on platelet aggregation and fibrinolytic activity, thyroid stimulatory activity, antioxidant, antibacterial, cytotoxic, anti-inflammatory and hypoglycaemic activities. Its phytochemical composition indicates the presence of diterpenoids, triterpenoids, steroids, longchain aliphatic tetrols, aliphatic esters, ferulates, lignans, carbohydrates, and a variety of inorganic ions besides minor amounts of sesamin and other unidentified constituents. A large number of compounds have been isolated from $C$. wightii and shown to possess assorted biological properties. In addition, crude extracts of the plant and their solvent fractions are connected with diverse pharmacological activities. Ethnopharmacological research on $C$. wightii is heartening as phytochemical profiling, nutritional and biological activities of the species could support the documented medicinal uses, nutritional and nutraceutical properties of $C$. wightii. Comprehensive research on phytochemical properties, biological activities, pharmacokinetics and clinical trials of $C$. wightii is required as this will present further confirmation for the nutritional, ethnopharmacology and nutraceutical potential of $C$. wightii. Further research should center on experimental in vitro, in vivo studies and toxicological evaluation of $C$. wightii and its phytochemical compounds.

\section{Conflict of interest}

The authors declare that no conflict of interest is associated with this work.

\section{Acknowledgments}

The authors would like to thank the Mr. Prabhat Kumar Jain, Geeta Parkhe and All supporting staff of Scan Research 
Laboratories, Bhopal (M.P.) who helped in the experiments during research work.

\section{References}

1. Devgun M, Nanda A, Ansari SH. Pterocarpus marsupium Roxb. A comprehensive review. Pharmacognosy reviews. 2009;3(6):359.

2. Prathap BC, Rajitha B, Anusha $\mathrm{CH}$, Nagasirisha $\mathrm{M}$ Madhusudhana Chetty C, Mohamed Saleem TS. Pterocarpus marsupium Roxb: A potent herb for life threatening diseases. Int J Res Phyt Pharm. 2012(2):75-83.

3. Kathryn AR, Connie MR, Jaime AY, Neal MD. Pharmacometrics of Stilbenes. Current Clinical Pharmacology. 2006;1(1):81101.

4. Kumar RS, Sivakumar T, Sunderam RS, Gupta M, Mazumdar UK, Gomathi P, et al. Antioxidant and antimicrobial activities of Bauhinia racemosa L. stem bark. Brazilian Journal of Medical and Biological Research 2005; 38: 1015-1024.

5. D.C. Singh, Srishti Dhyani, Gagandeep Kaur. A critical review on guggulu [Commiphora wightii (arn.) bhand.] \& its miraculous medicinal uses. International Journal of Ayurveda and Pharma Research 2015; 3(1):1-9.

6. Lr.Colonel. K.R.Kirtikar, Major B.D.Basu, Indian Medicinal Plants, Vol. 1, edited, enlarged and mostly rewritten by E.Blatter, J.F.Caius and K.S.Mhaskar, International Book Distributor, Dehradun; 528.

7. Priyavrat Sharma, Namarupajnanam, Chaukhambha Visvabharati, Varanasi, 2011; 72-73.

8. Prof. D. Shanth Kumar Lucas, Dravayaguna-vijnana, Vol. 2, Chaukhmabha Vishvabharati, Varanasi; 73

9. Om Prakash Rout, Rabinarayan Acharya, Sagar Kumar Mishra Oleo gum resin guggulu: a review of the medicinal evidence for its therapeutic properties. International Journal of Research in Ayurveda and Pharmacy 2012, 3(1), 15-21.

10. Raghunath K, Mitra R, Pharmacognosy of Indigenous drugs, Vol I, central council for research in Ayurveda and Siddha, India; 2005.p.354-373

11. Ravindra Sharma, Medicinal Plants of India, An Encyclopaedia, Daya Publishing House, Delhi, 2003; 68.

12. Indian Medicinal Plants, Forgotten Healers, by Prakash Paranjpe, Chaukhambha Sanskrit Pratishthan, Delhi; 91.

13. Goyal P, Chauhan A and Kaushik P (2010). Assessment of Commiphora wightii (Arn.) Bhandari (Guggul) as potential source for antibacterial agent, J. of Medicine and Medical Sciences 1(3), 071-075.

14. Lr.Colonel. K.R.Kirtikar, Major B.D.Basu, Indian Medicinal Plants, Vol. 1, edited, enlarged and mostly rewritten by E.Blatter, J.F.Caius and K.S.Mhaskar, International Book Distributor, Dehradun; 527.

15. Indian Medicinal Plants, Forgotten Healers, by Prakash Paranjpe, Chaukhambha Sanskrit Pratishthan, Delhi; 91.

16. Vaidya Vishnu Mahadev Gogte, Ayurvedic Pharmacology and Therapeutic uses of Medicinal Plants (Dravayagunavignyan), Chaukhambha Publications, New Delhi; 357.

17. The Ayurvedic Pharmacopoeia Of India, Part-1, Vol.1, Government Of India, Ministry of Health and Family Welfare, Department of Indian Systems of Medicine \& Homeopathy, 2001; 73-74.

18. Sarin YK, llustrated Manual of Herbal drugs used in Ayurvda, Council of scientific and Industrial research, Indian council of medical Research; 1996.p.330-331.

19. A. Bhati, "Essential oil from the resin of Commiphora mukul, Hook. Ex. stocks," Journal of the Indian Chemical Society, vol. 27, pp. 436-440, 1950.

20. V. K. Saxena and R. N. Sharma, "Constituents of the essential oil from Commiphora mukul gum resin," Journal of Medicinal and Aromatic Plant Sciences, vol. 20, pp. 55-56, 1998.

21. G. Rucker, "Monocyclic diterpenes from Indian gugul resin (Commiphora mukul)," Archiv der Pharmazie, vol. 305, no. 7, pp. 486-493, 1972.

22. R. S. Prasad and S. Dev, "Chemistry of ayurvedic crude drugsIV: guggulu (resin from commiphora mukul-4 absolute stereochemistry of mukulol," Tetrahedron, vol. 32, no. 12, pp. 1437-1441, 1976.

23. V. D. Patil, U. R. Nayak, and S. Dev, "Chemistry of ayurvedic crude drugs-II. Guggulu (resin from Commiphora mukul)-2: diterpenoid constituents," Tetrahedron, vol. 29, no. 2, pp. 341348, 1973.

24. J. A. Francis, S. N. Raja, and M. G. Nair, "Bioactive terpenoids and guggulusteroids from Commiphora mukul gum resin of potential anti-inflammatory interest," Chemistry and Biodiversity, vol. 1, no. 11, pp. 1842-1853, 2004.

25. H. Matsuda, T. Morikawa, S. Ando et al., "Absolute stereostructures of polypodane-type triterpenes, myrrhanol A and myrrhanone $\mathrm{A}$, from guggul-gum resin (the resin of Balsamodendron mukul)," Chemical and Pharmaceutical Bulletin, vol. 52, no. 10, pp. 1200-1203, 2004.

26. I. Kimura, M. Yoshikawa, S. Kobayashi et al., "New triterpenes, myrrhanol A and myrrhanone A, from guggul-gum resins, and their potent anti-inflammatory effect on adjuvant-induced airpouch granuloma of mice," Bioorganic and Medicinal Chemistry Letters, vol. 11, no. 8, pp. 985-989, 2001.

27. J. Xu, Y. Guo, P. Zhao et al., "Neuroprotective cadinane sesquiterpenes from the resinous exudates of Commiphora myrrha," Fitoterapia, vol. 82, no. 8, pp. 1198-1201, 2011.

28. L. O. Hanus, T. Rezankab, V. M. Dembitskya, and A Moussaieffa, "Myrrh-Commiphora chemistry," Biomedical Papers, vol. 149, no. 1, pp. 3-28, 2005.

29. V. D. Patil, U. R. Nayak, and S. Dev, "Chemistry of Ayurvedic crude drugs-I: Guggulu (resin from Commiphora mukul)-1: steroidal constituents," Tetrahedron, vol. 28, no. 8, pp. 23412352, 1972 .

30. K. K. Purushothaman and S. Chandrasekharan, "Guggulsterols from Commiphora mukul (Burseraceae)," Indian Journal of Chemistry Section B, vol. 14, pp. 802-804, 1976.

31. A. G. Bajaj and S. Dev, "Chemistry of ayurvedic crude drugs- V. Guggulu (resin from Commiphora mukul)-5 some new steroidal components and, stereochemistry of guggulsterol-I at C-20 and C-22," Tetrahedron, vol. 38, no. 19, pp. 2949-2954, 1982.

32. M. O. Fatope, S. K. S. Al-Burtomani, J. O. Ochei, A. O. Abdulnour S. M. Z. Al-Kindy, and Y. Takeda, "Muscanone: a 3-0-(1,8,14trimethylhexadecanyl) naringenin from Commiphora wightii," Phytochemistry, vol. 62, pp. 1251-1255, 2003.

33. H. K. Kakrani, "Flavonoids from the flowers of Commiphora mukul," Fitoterapia, vol. 52, no. 5, pp. 221-223, 1981.

34. V. Kumar and S. Dev, "Chemistry of ayurvedic crude drugs- VII guggulu (resin from Commiphora mukul)-6: absolute stereochemistry of guggultetrols," Tetrahedron, vol. 43, no. 24, pp. 5933-5948, 1987.

35. S.-L. Su, J.-A. Duan, Y.-P. Tang et al., "Isolation and biological activities of neomyrrhaol and other terpenes from the resin of Commiphora myrrha," Planta Medica, vol. 75, no. 4, pp. 351355, 2009.

36. H. Matsuda, T. Morikawa, S. Ando et al., "Absolute stereostructures of polypodane- and octanordammarane-type triterpenes with nitric oxide production inhibitory activity from guggulgum resins," Bioorganic and Medicinal Chemistry, vol. 12, no. 11, pp. 3037-3046, 2004.

37. S. Bose and K. C. Gupta, "Structure of Commiphora mukul gum I: nature of sugars present and the structure of aldobiouronic acid," Indian Journal of Chemistry Section A, vol. 2, pp. 57-60, 1966.

38. M. A. Ali and M. Hasan, "Chemical investigation of Commiphora mukul Engl. (Burseraceae)," Pakistan Journal of Scientific and Industrial Research, vol. 10, pp. 21-23, 1967.

39. G. V. Satyavati, "Guggulipid: a promising hypolipidemic agent from gum guggul (Commiphora wightii)," Economic and Medicinal Plant Research, vol. 5, pp. 48-82, 1991.

40. Wikipedia.org [home page on the internet] http://en.wikipedia.org/wiki/Commiphora_wightii.

41. K.Raghunathan and Miss. Roma Mitra, Pharmacognosy of Indigenous Drugs Vol.1, Central Council for Research in Ayurveda and Siddha, New Delhi, 2005; 360.

42. Satyavati GV (1991). A promising hypolipidemic agent from gum guggul (Commiphora wightii). Econ. Med. Plant Res. 5, 47-82.

43. Sushruta samhita, chapter 15, cerse 37-38 (chowkamba Sanskrit sirija, Varanasi) 1954,62

44. Pareek A and Pareek L K (2012). Commiphora wightii (Guggal) An Endangered Medicinal Plant of Rajasthan Needs Attention of Biotechnologists for Its Conservation. J. of Pharmaceutical, Biological and Chemical Sciences. 3(1), 83-89. 
45. Chaudhary (2012). Pharmacological Properties of Commiphora wightii Intern. J. of Pharma. and Pharmaceutical Sciences. 4(3), 73-75.

46. Polterait O (1997). Antioxidants and free-radical Scavengers of Natural origin, Current Org. Chem. 1415-1440.

47. Prior R L (2003). Fruit and vegetables in the prevention of cellular oxidative damage. American J. Clin. Nut. 78, 570-578.

48. Devasagayam T P, Tilak, J C and Boloor K K ( 2004). Free radicals and antioxidants in human health: Curr. Stat. Fut. Prosp. 52, 794-804.

49. Dubey D.,Prashant K. and Jain S.K. (2009). In-vitro antioxidant activity of the ethyl acetate extract of gum guggul (Commiphora mukul) Biological Forum - An Interna. J. 1(1), 32-35.

50. Nakayoma J and Yamada M.(1995). Suppression of active oxygen-indeed cyto- toxicity by flavonoids. Biochem. Pharmcol. 45, 265- 267.

51. mishra S A, Bhaishjaya(surbharti pakashan,varanasi)1996,193.

52. Vineet S.(2008), In situ conservation of Commiphora wightii a red -listed medicinal plant species of Rajasthan state, India. Final project report of IUCN.

53. Goyal P, Chauhan A and Kaushik P (2010). Assessment of Commiphora wightii (Arn.) Bhandari (Guggul) as potential source for antibacterial agent, J. of Medicine and Medical Sciences 1(3), 071-075.

54. Satyavati, G.V, Effect of an indigenous drugs (Guggulu) disorders of lipid metabolism with special reference to atherosclerosis and obesity (Medorog), 1966. Thesis submitted of the degree of D.Ay.M. (B.H.U) Brochure P.G.I.M. B.H.U:77.

55. Satyavati, G.V, Dwarakanath, C and Tripathi, S.N, Experimental studies on the hypocholesterolemic effect of C. mukul (Guggulu). Indian J. Med. Res. 1969; 57:10.

56. Shastry, V.V.S and Tripathi, S.N, Experimental and clinical studies on effect of Guggulu (C.mukul) in hyperlipidaemia and thrombosis, Jour. Res. Indian Med. 1968; 2(1):195.

57. Mehta, V.L, Malhotra, C.L, Katrah, N.S, The effects of various fractions of gum guggulu on experimentally produced hypocholesterolaemia. Indian. J. Physiol. \& Pharmacol. 1968; 12:87.

58. Malhotra C.L, Agarwal, Y.K, Mehta, V.L. and Prasad, D., The effect of various fractions of Gum guggulu on experimentally produced hypocholesterolaemia. Indian J. Med. Res. 1970; 51.(3):394.

59. Khanna, D.S, Agarwal, O.P, Gupta, S.K and Arora, R.B, A biochemical approach to anti-athero-sclerotic action of C.mukul on indigenous drug, in Indian domestic pigs, Indian J. Med. Res. 1969; 57:900.

60. Malhotra, S.C. and Ahuja, M.M.S, Effect of steroidal compound isolated from fraction A of Commiphora mukul on hepatic and aortic lipid content in rats fed on atherogenic diet, Indian J. Pharmacol. 1972; 4:110.

61. Das, D., Sharma, R.C and Arora, R.B, Anti-hyperlipidaemic activity of fraction ' $A$ ' of Commiphora mukul in monkeys. Indian j. Pharmacol. 1973; 5:283.

62. Kapoor, N.K. and Nityanand, S, Hypocholesterolaemic effect of the fraction isolated from the C.mukul (Guggulu) 1971, Paper presented at a seminar on disorders of lipid metabolism, held in New Delhi, (India) October; 15-16.

63. Nityanand, S and Kapoor, N.K, Hypocholesterolaemic effect of Commiphora mukul resin, Indian J. Expt. Biol. 1971; 9:376.

64. G. V. Satyavati, "Gum guggul (Commiphora mukul)-the success story of an ancient insight leading to a modern discovery," Indian Journal of Medical Research, vol. 87, no. 4, pp. 327-335, 1988.

65. S. Nityanand, J. S. Srivastava, and O. P. Asthana, "Clinical trials with gugulipid-a new hypolipidaemic agent," The Journal of the Association of Physicians of India, vol. 37, no. 5, pp. 323328, 1989.

66. S. K. Verma and A. Bordia, "Effect of Commiphora mukul (gum guggulu) in patients of hyperlipidemia with special reference to HDL-cholesterol," Indian Journal of Medical Research, vol. 87, no. 4, pp. 356-360, 1988.

67. V. Baldwa, V. Bhasin, P. Ranka, and K. Mathur, "Effects of Commiphora mukul (guggulu) in experimentally induced hyperlipemia and atherosclerosis,"The Journal of the
Association of Physicians of India, vol. 29, no. 1, pp. 13-17, 1981.

68. R. S.Hasani, N. Nayebi, L.Moradi, A.Mehri, B. Larijani, andM. Abdollahi, "The efficacy and safety of herbal medicines used in the treatment of hyperlipidemia; a systematic review," Current Pharmaceutical Design, vol. 16, no. 26, pp. 2935-2947, 2010.

69. R. Chander, A. K. Khanna, and N. K. Kapoor, "Lipid lowering activity of guggulsterone from Commiphora mukul in hyperlipaemic rats," Phytotherapy Research, vol. 10, no. 6, pp. 508-51,1996.

70. L. Mester, M. Mester, and S. Nityanand, "Inhibition of platelet aggregation by 'guggulu' steroids," Planta Medica, vol. 37, no. 4, pp. 367-369, 1979.

71. A. Bordia and S. K. Chuttani, "Effect of gum guggula on fibrinolysis and platelet adhesiveness in coronary heart disease," Indian Journal of Medical Research, vol. 70, no. 6, pp. 992-996, 1979.

72. S. Panda and A. Kar, "Gugulu (Commiphora mukul) induces triiodothyronine production: possible involvement of lipid peroxidation," Life Sciences, vol. 65, no. 12, pp. 137-141, 1999.

73. Y.B.Tripathi, O. P. Malhotra, and S. N. Tripathi, "Thyroid stimulating action of $Z$-guggulsterone obtained from Commiphora mukul," Planta Medica, vol. 50, no. 1, pp. 78-80, 1984.

74. Gujral, M.L., Sareen. K Tangri, K.K., Amma, M.K.P. and Roy, A.K., Anti-arthritic and anti-inflammatory activity of Gum guggul (Balsamodendron mukul Hook.) Indian J. Physiol. Pharmacol. 1960; 4:267.

75. Santha Kumari, G., Gujral, M.L. and Sareen, K., Further studies on the anti-arthritic and anti-infflammatory activities of gum guggul. Indian J. Physiol. Pharmacol. 1964; 8(2):36-37.

76. Arora, R.B, Kapoor, V., Gupta, S.K. and Sharma R.C., Isolation of crystalline steroidal compound from C.mukul and its antiinflammatory activity. Indian J. Expt. Biol. 1971; 9.403.

77. R. B. Arora, V. Taneja, R. C. Sharma, and S. K. Gupta, "Antiinflammatory studies on a crystalline steroid isolated from Commiphora mukul," Indian Journal of Medical Research, vol. 60, no. 6, pp. 929-931, 1972.

78. J. A. Francis, S. N. Raja, and M. G. Nair, "Bioactive terpenoids and guggulusteroids from Commiphora mukul gum resin of potential anti-inflammatory interest," Chemistry and Biodiversity, vol. 1, no. 11, pp. 1842-1853, 2004.

79. G. Chaudhary, "Pharmacological properties of Commiphora wightii Arn. Bhandari-an overview," International Journal of Pharmacy and Pharmaceutical Sciences, vol. 4, no. 3, pp. 7375, 2012.

80. M. L. Gujral, K. Sareen, K. K. Tangri, M. K. Amma, and A. K. Roy, "Antiarthritic and anti-inflammatory activity of gum guggul (Balsamodendron mukul Hook)," Indian Journal of Physiology and Pharmacology, vol. 4, pp. 267-273, 1960.

81. D. Khanna,G. Sethi, K. S. Ahn et al., "Natural products as a gold mine for arthritis treatment," Current Opinion in Pharmacology, vol. 7, no. 3, pp. 344-351, 2007.

82. M. Karan, P. Sarup, V. Suneja, and K. Vasisht, "Effect of traditional ayurvedic purification processes (sodhanvidhi) of guggulu on carrageenan-induced paw oedema in rats," Journal of Pharmaceutical and Biomedical Sciences, vol. 21,no. 5, pp. 15, 2012.

83. I. Kimura, M. Yoshikawa, S. Kobayashi et al., "New triterpenes, myrrhanol A and myrrhanone A, from guggul-gum resins, and their potent anti-inflammatory effect on adjuvant-induced airpouch granuloma of mice," Bioorganic andMedicinal Chemistry Letters, vol. 11, no. 8, pp. 985-989, 2001.

84. S. Verma, A. Jain, and V. B. Gupta, "Synergistic and sustained anti-inflammatory activity of guguul with the ibuprofen: a preliminary study," International Journal of Pharma and Bio Sciences, vol. 1, pp. 1-7, 2010.

85. B. B. Singh, L. C. Mishra, S. P. Vinjamury, N. Aquilina, V. J. Singh, and N. Shepard, "The effectiveness of Commiphora mukul for osteoarthritis of the knee: an outcomes study," Alternative Therapies in Health and Medicine, vol. 9, no. 3, pp. 74-79, 2003.

86. X.Wang, J. Greilberger, G. Ledinski, G. Kager, B. Paigen, and G. Jurgens, "The hypolipidemic natural product Commiphora mukul and its component guggulsterone inhibit oxidative modification of LDL," Atherosclerosis, vol. 172, no. 2, pp. 239246, 2004. 
87. R. Chander, F. Rizvi, A. K. Khanna, and R. Pratap, "Cardioprotective activity of synthetic guggulsterone ( $E$ and Zisomers) in isoproterenol inducedmyocardial ischemia in rats: a comparative study," Indian Journal of Clinical Biochemistry, vol. 18, no. 2, pp. 71-79, 2003.

88. M.K. P.Amma, N. Malhotra,R.K. Suri, O. P. Arya,H.M.Dani, and K. Sareen, "Effect of oleoresin of gum guggul (Commiphora mukul) on the reproductive organs of female rat," Indian Journal of Experimental Biology, vol. 16, no. 9, pp. 1021-1023, 1978.

89. D. M. Thappa and J. Dogra, "Nodulocystic acne: oral gugulipid versus tetracycline," Journal of Dermatology, vol. 21, no. 10, pp. 729-731, 1994.

90. R. Bellamkonda, K. Rasineni, S. R. Singareddy et al., "Antihyperglycemic and antioxidant activities of alcoholic extract of Commiphora mukul gum resin in streptozotocin induced diabetic rats," Pathophysiology, vol. 18, no. 4, pp. 255261, 2011.

91. B. Sharma, R. Salunke, S. Srivastava, C.Majumder, and P. Roy, "Effects of guggulsterone isolated from Commiphora mukul in high fat diet induced diabetic rats," Food and Chemical Toxicology, vol. 47, no. 10, pp. 2631-2639, 2009.

92. A. Sharma, V. Kumar Patel, S. Rawat, P. Ramteke, and R. Verma, "Identification of the antibacterial component of some Indian medicinal plants against klebsiella pneumoniae," International Journal of Pharmacy and Pharmaceutical Sciences, vol. 2, no. 3, pp. 123-127, 2010.

93. P. Goyal, A. Chauhan, and P. Kaushik, "Assessment of Commiphora wightii (Arn.) Bhandari (Guggul) as potential source for antibacterial agent," Journal of Medicine and Medical Sciences, vol. 1, no. 3, pp. 71-75, 2010.

94. K. B. Ishnava, Y. N. Mahida, and J. S. S. Mohan, "In vitro assessments of antibacterial potential of Commiphora wightii (Arn.) Bhandari. gum extract," Journal of Pharmacognosy and Phytotherapy, vol. 2, no. 7, pp. 91-96, 2010.

95. C. D. Romero, S. F. Chopin, G. Buck, E. Martinez, M. Garcia, and L. Bixby, "Antibacterial properties of common herbal remedies of the southwest," Journal of Ethnopharmacology, vol. 99, no. 2, pp. 253-257, 2005.
96. N. Zhu, M. M. Rafi, R. S. DiPaola et al., "Bioactive constituents from gum guggul (Commiphora wightii)," Phytochemistry, vol. 56, no. 7, pp. 723-727, 2001.

97. D. Xiao, Y. Zeng, L. Prakash, V. Badmaev, M. Majeed, and S. V. Singh, "Reactive oxygen species-dependent apoptosis by gugulipid extract of ayurvedic medicine plant Commiphora mukul in human prostate cancer cells is regulated by c-Jun Nterminal kinase," Molecular Pharmacology, vol. 79, no. 3, pp. 499-507, 2011

98. Prof. D. Shanth Kumar Lucas, Dravayaguna-vijnana, Vol. 2, Chaukhmabha Vishvabharati, Varanasi; 76

99. J. R. Bhatt, M N. B. Nair and H. Y. Mohan Ram, "En- hancement of Oleo Gum Resin Production in Commi- phora wightii by Improved Tapping Technique," Current Science, Vol. 58, No. 7, 1989, pp. 349-357.

100. R. S. Mertia, N. K. Sinha, B. K. Kandpal and D. Singh, "Evaluation of Indian Myrrh (Commiphora wightii) Landraces for Hyper Arid Thar Desert," Indian Journal of Agricultural Sciences, Vol. 80, No. 10, 2010, pp. 869-871.

101. C. S. Reddy, S. L. Meena, P. H. Krishna, P. D. Charan and K. C. Sharma, "Conservation Threat Assessment of Commiphora wightii (Arn.) Bhandari-An Economically Important Species," Taiwania, Vol. 57, No. 3, 2012, pp. 288-293.

102. S. A. Masten, Gum Guggul and Some of Its Steroidal Constituents: Review of Toxicological Literature, vol. 2, US Department of Health and Human Services, National Toxicology Program (NTP), National Institute of Environmental Health Sciences (NIEHS), National Institutes of Health, Durham, NC, USA, 2005.

103. L. A. Nohr, L. B. Rasmussen, and J. Straand, "Resin from the mukul myrrh tree, guggul, can it be used for treating hypercholesterolemia? A randomized, controlled study," ComplementaryTherapies in Medicine, vol. 17, no. 1, pp. 16-22, 2009.

104. P. O. Szapary, M. L. Wolfe, L. T. Bloedon et al., "Guggulipid for the treatment of hypercholesterolemia: a randomized controlled trial," Journal of the American Medical Association, vol. 290, no. 6, pp. 765-772, 2003. 